\title{
Análisis de la Maqueta Táctil en la Perspectiva del Diseño Universal para el Aprendizaje
}

\author{
Verônica Yumi Kataoka, Aida Carvalho Vita \\ e Irene Mauricio Cazorla
}

\section{Resumen}

Este artículo tiene como objetivo analizar el Modelo Táctil (MT) desde la perspectiva del Diseño Universal para el Aprendizaje (DUA). El MT está compuesto por piezas y por la secuencia de enseñanza Paseos Aleatorios de Jefferson (SE-PAJ), que aborda el concepto de chance. Se desarrolló una discusión teórica en dos etapas, de las cuales solo se evaluó en este artículo la tercera tarea de SE-PAJ y las partes involucradas. Las categorías de análisis de la primera etapa fueron los puntos de verificación de las tres directrices del principio 1, y en la segunda etapa solo las directrices de los principios 2 y 3 . Los resultados parecen indicar que esta tarea y las piezas cumplen satisfactoriamente con los principios y directrices de la DUA para abordar el concepto de chance. Por ejemplo, la directriz «Clarificar terminología y símbolos», fue contemplada porque antes del desarrollo de esta tarea, el alumno tuvo la posibilidad de experimentar, en las tareas anteriores, situaciones que pueden favorecer la familiarización con la terminología, destacando el uso del término chance en lugar de probabilidad, estando también asociado con el concepto de equidad. Se espera que este artículo contribuya con estudios futuros que involucren la propuesta de materiales didácticos desde la perspectiva de DUA y, por lo tanto, ayuden a una inclusión más realista e integradora de todos los estudiantes.

Palabras clave: Diseño de Aprendizaje Universal, Maqueta Táctil, Secuencia de Enseñanza, Concepto de Chance. 


\section{Análise da Maquete Tátil na Perspectiva do Desenho Universal para Aprendizagem}

\section{Resumo}

Este artigo tem como objetivo analisar a Maquete Tátil (MT) na perspectiva do Desenho Universal para Aprendizagem (DUA). A MT é composta por peças e pela Sequência de Ensino Passeios Aleatórios do Jefferson (SE-PAJ), aborda o conceito de chance. Desenvolveu-se uma discussão teórica em duas etapas, da qual foi avaliada neste artigo somente a terceira tarefa da SE-PAJ e as peças envolvidas. As categorias de análise da primeira etapa foram os pontos de verificação das três diretrizes do princípio 1, e na segunda etapa apenas as diretrizes dos princípios 2 e 3 . Os resultados parecem indicar que esta tarefa e as peças atendem satisfatoriamente aos princípios e diretrizes do DUA para o estudo do conceito de chance. A exemplo, a diretriz «Esclarecer terminologia e símbolos», foi contemplada porque antes do desenvolvimento dessa tarefa, o aluno teve possibilidade de vivenciar, nas tarefas anteriores, situações que podem favorecer a familiarização com a terminologia, destacando o uso do termo chance ao invés de probabilidade, sendo associado também ao conceito de justo. Espera-se que este artigo contribua com futuros estudos que envolvam a proposição de materiais didáticos na perspectiva do DUA e, por conseguinte, auxiliar uma inclusão mais realística e integradora de todos os alunos.

Palavras chave: Desenho Universal da Aprendizagem, Maquete Tátil, Sequência de Ensino, Conceito de Chance. 


\title{
Analysis of Tactile Model in the Perspective of Universal Design for Learning
}

\begin{abstract}
This article aims to analyze the Tactile Model (MT) based on the perspective of Universal Design for Learning (DUA). MT is composed of pieces and Jefferson's Random Walks Teaching Sequence (SE-PAJ), which addresses the concept of chance. The theoretical discussion was developed in two stages, from which in this article was evaluated only the third task of SE-PAJ and the pieces involved. The analytical categories of first stage were the checkpoints of three guidelines of principle 1, and in the second stage, only the guidelines of principles 2 and 3 . The results seem to indicate that this task and the pieces satisfactorily meet the principles and guidelines of the DUA to approach the concept of chance. For example, the guideline «Clarify terminology and symbols» was included because before the development of this task, students had possibility to experience situations in previous tasks which promoted familiarization with the terminology, emphasizing the use of terms such chance instead probability, and is also associated with the concept of fair. It is expected that this article will contribute to studies involving the proposition of teaching materials from the perspective of DUA and, therefore, support a more realistic and integrative inclusion of all students.
\end{abstract}

Keywords: Universal Design of Learning, Tactile model, Teaching Sequence, Chance.

Análisis de la Maqueta Táctil en la Perspectiva del Diseño Universal para el Aprendizaje

Autor 1: Verônica Yumi Kataoka

Campus Soane Nazaré de Andrade, Rodovia Jorge Amado, km 16, Bairro Salobrinho, Código Postal 45662-900. Ilhéus, Bahia, Brasil

+55 (73) 991995280

Universidade Estadual de Santa Cruz (Brasil)

vykataoka@uesc.br

Autor 2: Aida Carvalho Vita

Campus Soane Nazaré de Andrade, Rodovia Jorge Amado, km 16, Bairro Salobrinho, Código Postal 45662-900. Ilhéus, Bahia, Brasil
+55 (73) 98802-6418

Universidade Estadual de Santa Cruz (Brasil)

aida2009vita@gmail.com

Autor 3: Irene Mauricio Cazorla

Campus Soane Nazaré de Andrade, Rodovia Jorge Amado, km 16, Bairro Salobrinho, Código Postal 45662-900. Ilhéus, Bahia, Brasil +55(73) 991779913

Universidade Estadual de Santa Cruz (Brasil) icazorla@uol.com.br 


\section{Introdução}

Neste artigo temos como objetivo apresentar um estudo teórico, parte de um projeto de pesquisa desenvolvido por Kataoka, Carvalho y Cazorla (2017), voltado a analisar a Maquete Tátil (MT) na perspectiva do Desenho Universal para Aprendizagem. A MT é um material didático, composto de peças e tarefas da Sequência de Ensino Passeios Aleatórios do Jefferson (SE PAJ), por meio do qual pode ser abordado, de forma direta, o conceito de chance com eventos equiprováveis e não equiprováveis; e, de forma indireta, outros conceitos probabilísticos $^{(1)}$, a serem explorados pelos professor pós-aplicação. Utilizamos o termo chance em acordo com a definição apresentada por Watson (2006), como «uma aproximação da probabilidade, para distinguir aspectos mais intuitivos e experimentais do estudo da probabilidade teórica baseada nos espaços amostrais» (p. 128).

Vivemos uma época em que é cada vez mais comum a mídia valer-se de termos probabilísticos para caracterizar diversas situações cotidianas como, por exemplo, as chances de chover ou de um time passar para uma fase de um campeonato, os riscos de se adquirir determinado tipo de doença ou de se contratar um seguro, os resultados de pesquisas eleitorais. E, de acordo com Gal (2005), a capacidade de ler, interpretar, transmitir e avaliar criticamente informações probabilísticas é o que se denomina de «letramento probabilístico», sendo que esta habilidadejá pode ser desenvolvida pelos alunos na escola. Nessa direção, o Ministério de Educação do Brasil, reconhecendo a importância do pensamento probabilístico na promoção de habilidades e competências necessárias para o exercício da cidadania, incorporou conceitos elementares desse conteúdo no currículo de Matemática para todas as séries da Educação Básica, por meio dos Parâmetros Curriculares Nacionais (Brasil, 1997, 2006); e mais recentemente pela Base Nacional Comum Curricular (Brasil, 2018). Até mesmo o Referencial Curricular Nacional da Educação Infantil (Brasil, 1998a), ao sinalizar que a criança da Educação Infantil pode desenvolver o raciocínio abstrato manipulando objetos concretos, preconiza indiretamente a abordagem de conceitos probabilísticos.

Mas, apesar das orientações curriculares, Cazorla (2006) afirma que a inserção efetiva do ensino de Estatística e Probabilidade na escola ainda enfrenta grandes desafios, como: a formação de professores, que na sua formação inicial ou não estudaram esses conteúdos ou, quando o fizeram, não trabalharam os aspectos relacionados à didática; a escassez de materiais didáticos e softwares computacionais, dentre outros. Corroborando essas considerações, Walichinski e Santos Júnior (2013) destacam a necessidade de elaborar e validar materiais didáticos acessíveis ao professor para o ensino desses conteúdos.

Nesta perspectiva de proposição de materiais didáticos, Vita (2012) desenvolveu a primeira versão da MT para abordar, com alunos videntes e cegos da Educação Básica, conceitos básicos de Probabilidade, tomando como base as orientações para o trabalho com alunos com necessidades educacionais especiais, contidas nos documentos oficiais, tais como Projeto Escola Viva - PEV (Brasil, 2005) e Parâmetros Curriculares Nacionais: Adaptações Curriculares - PCN: AC (Brasil, 1998b).

Ademais, ainda que legalmente observemos mudanças substanciais no processo social de inclusão com validação de diversos documentos oficiais que orientam esse movimento (Brasil, 1998b, 2005, 2010; Decretos Br, 2008, 2011; Resolução Br 2009) e verifiquemos um crescente número de alunos com deficiência matriculados no ensino regular, reconhecemos que, para a efetiva inclusão escolar, inúmeras providências precisam ser implementadas para garantir a permanência deles na escola e thes proporcionar acesso aos meios de aprendizagem escolar.

E nesse sentido, refletimos que uma dessas providências seria propor uma política educacional voltada para a aprendizagem de todos, ou seja, fomentar sequências de ensino e materiais didáticos que possibilitem promover condições de igualdade visando à inclusão de alunos de todos os alunos 
independentemente de suas especificidades, tais como, idades, habilidades ou limitações.

Concebemos uma Sequência de Ensino como um «conjunto de situações elaboradas e dispostas de maneira que sejam abordados conceitos previamente selecionados para serem trabalhados» (Santana, 2010, p. 113).

E, então, desde 2012, o nosso grupo de pesquisa vem desenvolvendo estudos visando ao aperfeiçoamento de um material didático, com aplicações feitas com alunos videntes, cegos, um autista e um hiperativo, de diferentes níveis de ensino (da Educação Infantil até o Doutorado) e analisada à luz de teorias da Educação Matemática. Como exemplo, cita-se o projeto de Vita et al. (2016), em que a MT foi estudada pela Teoria da Instrumentação, de Rabardel (1995), proveniente da Ergonomia Cognitiva, e pela Teoria dos Campos Conceituais, de Vergnaud (1983).

Neste artigo, desafiamo-nos a analisar, pela primeira vez, a MT, na sua última versão proposta pelos Kataoka, Carvalho y Cazorla (2017), pelos princípios do Desenho Universal para Aprendizagem, considerando justamente os resultados dessas pesquisas anteriores que demonstraram que o uso desse material por pessoas com diferentes condições físicas, sensoriais, intelectuais e sociais foi versátil e eficiente. Como já orientado pela Lei $n .013 .146$ (Br, 2015) de Inclusão da Pessoa com Deficiência no Livro 1 (Título I, Capítulo I, Artigo 3ㅜㅜ inciso II), que prevê o uso dos princípios do Desenho Universal (DU) para «concepção de produtos, ambientes, programas e serviços a serem usados por todas as pessoas, sem necessidade de adaptação ou de projeto específico [...]» (p.1).

0 Desenho Universal surgiu no campo da arquitetura e provocou uma mudança nos projetos urbanos, na arquitetura e no design, inclusive de produtos. De acordo com Nunes e Nunes Sobrinho (2008), o DU «representa uma superação da arquitetura dirigida para um homem ideal, o homem padrão, comprometendo-se assim com a diversidade humana» (p. 270). Mas, a aplicação dos princípios do DU é apontada por vários estudos, a exemplo de Courey et al. (2012), como úteis à educação no sentido de garantir a todos os alunos acesso à aprendizagem. Assim, foi proposta, no início dos anos 1990, pelos pesquisadores do Center for Applied Special Technology - Cast, uma extensão do DU, denominada «Desenho Universal para Aprendizagem (DUA)». Segundo Pastor, Serrano e Del Río (2014), o DUA pode ser definido como sendo um enfoque didático que pretende aplicar os princípios do DU no desenho de um currículo mais flexível, englobando desde o princípio até os diferente níveis educativos, possibilitando, assim, aos alunos progredirem em suas aprendizagens.

0 entendimento desses autores ratifica as ideias presentes no documento elaborado pelo Movimento Down (2015), em que o DUA é um conjunto de possibilidades, materiais flexíveis, técnicas e estratégias, que busca ampliar a aprendizagem de alunos com ou sem deficiência, universalizando a aprendizagem, à medida atende um maior número possivel de alunos.

\section{Desenho Universal para Aprendizagem (DUA)}

0 DUA, conforme o Cast (2011), tem sua base conceitual ancorada na neurociência, que entende que 0 cérebro é formado por um conjunto de redes interconectadas e que a aprendizagem é constituída por três importantes delas: a afetiva, a que determina a capacidade de 0 aluno se envolver com a aprendizagem -o porquê da aprendizagem; a segunda rede, a que reconhece, ou seja, a que transforma as informações em conhecimento- o quê da aprendizagem; e a terceira rede, a que estabelece a estratégia, a ligada à organização e ao planejamento de ações ambientes -o como da aprendizagem.

De acordo ainda com o Cast (2011), o uso, mais especificamente, dos princípios do DUA pode guiar a criação de objetivos educacionais, métodos, materiais e avaliações que atendam a todos os alunos. Entretanto, não pretende ofertar uma solução úni- 
ca, mas sim, uma abordagem flexível, que pode ser ajustada conforme as necessidades individuais. Em assim sendo, infere-se que, tomando como base os princípios do DUA, seria possível analisar os materiais didáticos, a fim de verificar se, de fato, estes atendem às diferentes realidades educacionais dos alunos. Para o Cast (2011), o DUA pode:

ajudar a lidar com a variabilidade do aluno, sugerindo flexibilidade nos objetivos, métodos, materiais e avaliações que capacitam os professores a atender a essas necessidades variadas. Currículos que são criados usando DUA são projetados desde o início para atender às necessidades de todos os alunos. [...] A estrutura DUA incentiva a criação de designs flexíveis desde o início que tenham opções personalizáveis, que permitam que todos os alunos progridam de onde estão e não de onde imaginamos que deveriam estar. As opções para realizar isso são variadas e robustas o suficiente para fornecer instruções eficazes a todos os alunos. (p. 4)

Considerando esses pressupostos e as três redes, supracitadas, o Cast (2011) estabeleceu três princípios norteadores do DUA, sendo que para cada um foram propostas três diretrizes. Calegari, da Silva e da Silva (2014) entendem que, seguindo estes princípios, é possível elaborar uma proposta de «aprendizagem flexível, além de estratégias e ferramentas que permitem aos alunos a escolha e a personalização que serão realizadas, de acordo com suas necessidades de aprendizagem» (p. 43). Quanto às diretrizes, o Cast (2011) esclarece que:

não se destinam a ser uma «receita», mas sim, como um conjunto de estratégias que podem ser empregadas para superar as barreiras inerentes à maioria dos currículos. As diretrizes podem servir de base para a construção das opções e da flexibilidade que são necessárias para maximizar as oportunidades de aprendizagem. Em muitos casos, os professores descobrem que muitas dessas diretrizes já estão incorporadas em sua prática [ênfase adicionada]. (p.12)

A opção neste estudo pelo uso dos princípios e das diretrizes propostos pelo Cast se deve ao fato de terem sido os pesquisadores deste Conselho os desenvolvedores do DUA, sendo, então, a referência básica e principal sobre o assunto. No Quadro 1, apresentamos uma breve descrição dos três princípios do DUA e suas diretrizes (Cast, 2011). (Quadro 1)

Refletindo sobre esses princípios e diretrizes, observamos que o DUA amplia a ideia de que, seja qual for o ambiente de ensino e aprendizagem, este deve incluir todos os alunos, apresentando metas flexíveis que podem ser ajustadas e personalizadas para atender particularidades e/ou necessidades específicas. Estando, assim, em consonância com as ideias de Chtena (2016) que afirma que o DUA pode nortear a elaboração um currículo que atenda às necessidades, às capacidades e aos interesses de todos os alunos, ao invés de meramente ajustá-lo, conforme necessário.

Sendo assim, essa proposta inspira a construção de um currículo adaptável, acessível e adequado, isto é, que proporcione modos múltiplos de apresentação, de ação e expressão e de engajamento. Ao analisarmos a maquete tátil (MT), de acordo com os princípios e as diretrizes do DUA, objetivamos conhecer sua predisposição para promover a participação e a autonomia dos alunos durante o processo de abordagem de conceitos probabilísticos e, por conseguinte, esperamos contribuir com a prática do professor que ensina Matemática, no sentido de articular um processo de inclusão mais integrador. 


\begin{tabular}{|c|c|c|}
\hline Princípio & Diretriz & Descrição da diretriz \\
\hline \multirow{3}{*}{$\begin{array}{l}\text { 1. Proporcionar } \\
\text { aos alunos modos } \\
\text { múltiplos de } \\
\text { apresentação } \\
\text { das atividades, } \\
\text { tendo como } \\
\text { característica o } \\
\text { meio pelo qual a } \\
\text { informação the é } \\
\text { transmitida. }\end{array}$} & 1.1 & $\begin{array}{l}\text { Proporcionar opções para a percepção: as estratégias de ensino devem ser } \\
\text { criadas para possibilitar opções para que os alunos personalizem a exibição } \\
\text { de informações; assim como alternativas de informações auditivas e visuais, } \\
\text { visando reduzir as barreiras da aprendizagem e garantir que as informações } \\
\text { principais sejam igualmente perceptíveis a todos os alunos. }\end{array}$ \\
\hline & 1.2 & $\begin{array}{l}\text { Oferecer opções para o uso da linguagem, expressões matemáticas e símbo- } \\
\text { los: as estratégias devem fornecer opções que definam o vocabulário e os } \\
\text { símbolos; que apoiem a decodificação de texto ou notação matemática; que } \\
\text { promovam a compreensão em diversas línguas; que ilustrem com exemplos } \\
\text { utilizando diferentes mídias. }\end{array}$ \\
\hline & 1.3 & $\begin{array}{l}\text { Ofertar opções para a compreensão: as estratégias devem evidenciar inte- } \\
\text { rações, ideias principais e conexões; orientar o processamento da infor- } \\
\text { mação, a visualização e a manipulação. }\end{array}$ \\
\hline \multirow[t]{3}{*}{$\begin{array}{l}\text { 2. Proporcionar } \\
\text { modos múltiplos } \\
\text { de ação e } \\
\text { expressão }\end{array}$} & 2.1 & $\begin{array}{l}\text { Proporcionar opções para a interação fisica: as estratégias de ensino devem } \\
\text { ser pensadas para oferecer opçôes para interação física, diversificando-se os } \\
\text { métodos de resposta e o percurso e otimizando o acesso a instrumentos e } \\
\text { tecnologias de apoio. }\end{array}$ \\
\hline & 2.2 & $\begin{array}{l}\text { Oferecer opções para a expressão e a comunicação: as estratégias devem favo- } \\
\text { recer o uso de meios midiáticos múltiplos para a comunicação, de instrumen- } \\
\text { tos múltiplos para a construção e composição; além de construir fluências } \\
\text { com níveis graduais de apoio à prática e ao desempenho. }\end{array}$ \\
\hline & 2.3 & $\begin{array}{l}\text { Propiciar opções para as funções executivas: as estratégias devem oferecer } \\
\text { opções de funções executivas, no sentido de orientar o estabelecimento de } \\
\text { metas adequadas; apoiar o planejamento e a estratégia de desenvolvimento; } \\
\text { fornecer opções que facilitem a gestão da informação e recursos e que refor- } \\
\text { cem a capacidade para monitorar o progresso do aluno. }\end{array}$ \\
\hline \multirow{3}{*}{$\begin{array}{l}\text { 3. Proporcionar } \\
\text { modos múltiplos } \\
\text { de envolvimento, } \\
\text { apresentando, } \\
\text { assim, como } \\
\text { característica } \\
\text { principal os } \\
\text { meios pelos } \\
\text { quais os alunos } \\
\text { estão engajados } \\
\text { no processo de } \\
\text { aprendizagem }\end{array}$} & 3.1 & $\begin{array}{l}\text { Proporcionar opções para incentivar o interesse: as estratégias específicas de } \\
\text { ensino devem ser sugeridas para despertar e aumentar a escolha individual e } \\
\text { a autonomia; para melhorar a relevância, valor e autenticidade; para minimi- } \\
\text { zar a insegurança e a ansiedade. }\end{array}$ \\
\hline & 3.2 & $\begin{array}{l}\text { Oferecer opções para o suporte ao esforço e à persistência: as estratégias de } \\
\text { ensino devem, para sustentar o esforço e a persistência: elevar a relevância } \\
\text { das metas e objetivos; fomentar a colaboração e o sentido de comunidade; } \\
\text { elevar o esforço ao saber adquirido. }\end{array}$ \\
\hline & 3.3 & $\begin{array}{l}\text { Ofertar opções para a autorregulação: as estratégias devem ser específicas } \\
\text { para fornecer opções de autorregulação a fim de: promover expectativas e } \\
\text { antecipações que otimizem a motivação; facilitar a capacidade individual de } \\
\text { superar dificuldades; desenvolver a autoavaliação e a reflexão. }\end{array}$ \\
\hline
\end{tabular}

\section{Quadro 1.}

Princípios e diretrizes do DUA.

Fonte: elaborado pelos autores com base em informações retiradas do Cast (2011). 


\section{A Maquete Tátil}

A Maquete Tátil (MT) é constituída por peças e pela Sequência de Ensino 0s Passeios Aleatório do Jefferson (SE PAJ). A SE PAJ foi proposta inicialmente por Vita (2012), mas ela foi sendo alterada, de acordo com os resultados das nossas pesquisas anteriores, buscando sempre adequar as suas tarefas às diversas realidades educacionais que foram sendo vivenciadas. Neste estudo, apresentamos sua última versão. As peças, detalhadas a seguir, são: tabuleiro, casas, presentes, fichas em EVA (numeradas e com letras), porta-copos, colmeias e campainha.

Os tabuleiros são de dois tamanhos: o normal, construído no chão com dimensões de $3 \times 3 \mathrm{~m}$ (Figura 1a) e a miniatura, feito com papelão e EVA, de dimensões $30 \times 30 \mathrm{~cm}$ (Figura 1b). 0 tabuleiro no

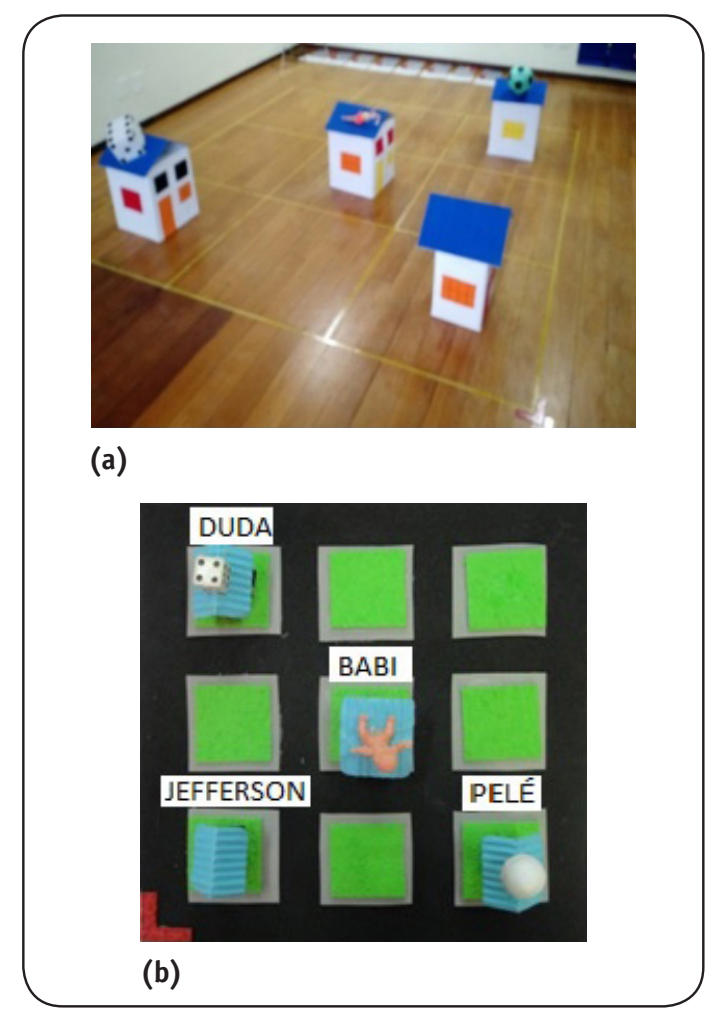

Figura 1.

Tabuleiros 3 amigos e casas normais (a) e miniaturas (b).

Fonte: Kataoka, Carvalho y Cazorla (2017).

chão é subdivido em nove quadrados, representando as quadras, já na miniatura as nove quadras estão em relevo. As casas são de dois tamanhos, normal (Figura 1a) e miniatura (Figura 1b), ambas em papelão e, quando coladas nos dois tabuleiros, estes passam a ser chamados de bairros.

Os presentes são colados nos telhados das casas, sendo também de dois tamanhos: normal a partir de dados em papelão $15 \times 15 \mathrm{~cm}$, bonecas e bolas de plástico (Figura 2a); e miniaturas com dados de $1 \times 1 \mathrm{~cm}$, bonecas plásticas e bolas de isopor (Figura $2 b$ ).

Os presentes fazem parte da coleção de cada um dos amigos e são dados por Jefferson quando os visita, como descrito na história da SE PAJ versão 3 amigos $^{(2)}$ (Figura 3).
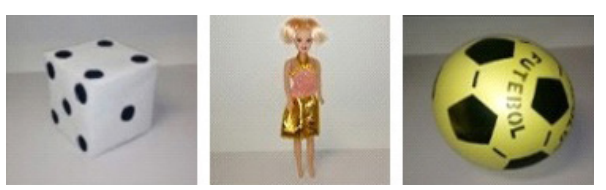

(a)

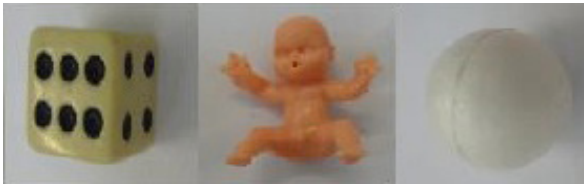

(b)
Figura 2.

Presentes normais (a) e miniaturas (b). Fonte: Kataoka, Carvalho y Cazorla (2017). 


\section{«OS PASSEIOS ALEATÓRIOS DE JEFFERSON 3 amigos»}

0 Jefferson e seus amigos vieram morar neste bairro novo. Os nomes dos amigos são: Duda, Babi e Pelé. Cada amigo coleciona um tipo de objeto, sendo que Duda coleciona dados, Babi coleciona bonecas e Pelé coleciona bolas. Jefferson costumava visitar seus amigos nos mesmos dias da semana em uma ordem preestabelecida: 2.a feira, Duda; 4.a feira, Babi; e 6.a feira, Pelé. Mas, para tornar mais emocionante os encontros, a turma combinou que a visita seria definida por sorteio, da seguinte forma: Jefferson deve tocar uma campainha; se sair o som «pim», andará uma quadra para FRENTE, se sair o som «pom», uma quadra para DIREITA. Cada jogada representa andar uma quadra. A distância da casa de Jefferson à casa de cada um dos amigos é sempre de duas quadras, assim ele deve tocar a campainha duas vezes para poder chegar à casa de um dos amigos e dar um presente para a sua coleção.

Figura 3.

História da SE PAJ versão 3 amigos.

Fonte: Kataoka, Carvalho y Cazorla (2017).

As fichas em EVA, no tamanho normal $(6 \mathrm{~cm} \times 6 \mathrm{~cm})$, podem ser de dois tipos: enumeradas de 1 a 15 (Figura 4a), e com letras, sendo uma face marcada com a letra $F$ e outra com a letra $D$, indicando a movimentação de Jefferson no tabuleiro, Frente e Direita, respectivamente (Figura 4b). Há também as fichas com letras em miniatura no tamanho de $2 \mathrm{~cm} \times 2 \mathrm{~cm}$. Destacamos que as fichas possuem ainda, no canto inferior esquerdo, os números ou letras em Braille. A peça denominada porta-copos (Figura $5 a$ ) tem a função de organizar, por tipo, os presentes (miniaturas) que Jefferson dá aos seus amigos e as fichas em miniaturas. Já as colmeias são de dois tamanhos: normal, feito de papelão, apresentando apenas 1 linha e 6 colunas (Figura $5 b$ ) e miniatura com 9 linhas e 6 colunas (Figura 5c), que servem para o registro, com as fichas em EVA, dos caminhos percorridos por Jefferson, nas visitas a seus amigos,

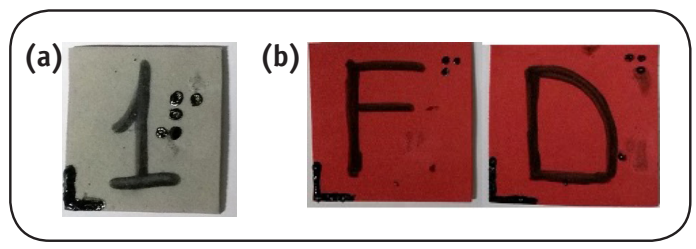

Figura 4.

Exemplos de fichas em EVA com número (a) e letras (b). Fonte: Kataoka, Carvalho y Cazorla (2017). bem como para os resultados da experimentação e construção de pictogramas 3D. Já a campainha é um dispositivo que possui dois botões e duas luzes de led e tem por finalidade reproduzir sorteios aleatórios (Figura 5d). Quando acende a luz de cor verde, produz um som «Pim», que representa o movimento para Frente no tabuleiro; e a luz vermelha emite um som «Pom», que indica o movimento para a Direita.

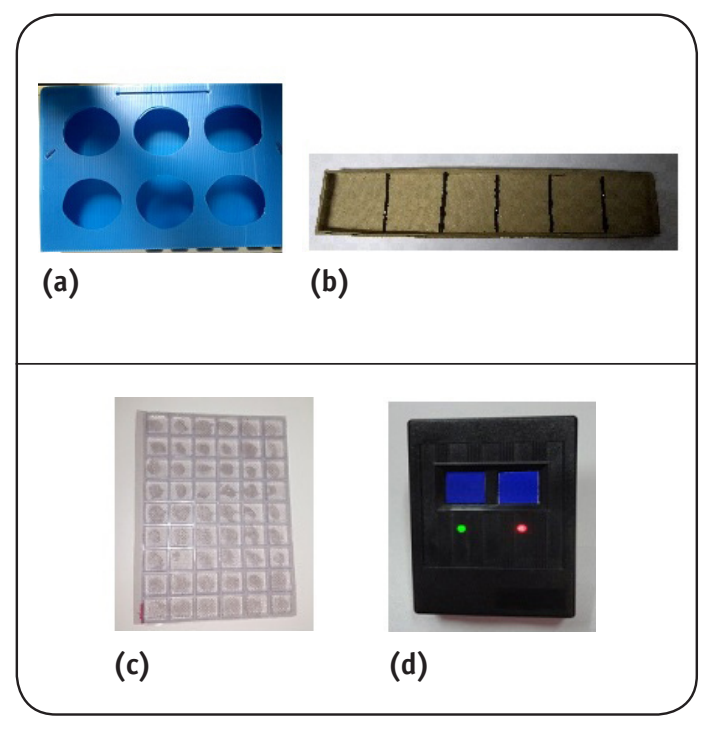

Figura 5.

Porta copos (a), Colmeia normal (b), Colmeia em miniatura (c), Campainha (e). Fonte: Kataoka, Carvalho y Cazorla (2017). 
A Sequência de Ensino Passeios Aleatórios do Jefferson (SE PAJ) é composta de cinco tarefas, denominadas: situação da ciranda; situação do reconhecimento do bairro; situação dos caminhos possíveis; situação da experimentação aleatória; situação da SE PAJ 5 amigos. Para seu desenvolvimento, inicialmente apresenta-se um contexto, para que $o$ aluno tenha que pensar na solução, conside- rando principalmente suas vivências cotidianas. Em seguida, fomenta-se a discussão dos registros de forma oral ou escrita; e, por fim, faz-se uma roda de conversa, em que se extraem respostas para outros questionamentos, oportunizando reflexões conjuntas. A seguir, descreveremos de forma resumida, no Quadro 2, essas tarefas, com exceção da terceira que será apresentada na seção «Análise: primeira etapa».

\begin{tabular}{|c|c|}
\hline Tarefa & Descrição \\
\hline 1..$^{a}$ & $\begin{array}{l}\text { Pode ser explorado o conceito de chance com eventos equiprováveis e não equiprováveis. } 0 \text { profes- } \\
\text { sor inicia, explicando que o tabuleiro no chão é um bairro novo, com nove quadras, e as pessoas só } \\
\text { podem se movimentar neste bairro indo para Frente ou para Direita. Diz que eles irão se movimentar } \\
\text { no tabuleiro em forma de brincadeira, utilizando a campainha (faz simulações). Divide os alunos em } \\
\text { duplas, dizendo que um irá tocar a campainha, e o outro vai se movimentar; mas que antes é ne- } \\
\text { cessário determinar a ordem em que as duplas vão iniciar a brincadeira. Para tal, forma um círculo } \\
\text { com um representante de cada dupla, e canta a música de ciranda: «UNIDUNITÊ, SALAMÊMINGUÊ, UM } \\
\text { SORVETE COLORÊ, O ESCOLHIDO FOI VOCÊ!», apontando para um aluno a cada sílaba, e o aluno em que } \\
\text { a música parar será o primeiro a brincar. Faz os seguintes questionamentos: «Vocês acham que essa } \\
\text { maneira de escolhermos quem será a primeira dupla que vai começar a brincadeira no tabuleiro é jus- } \\
\text { ta? Ou seja, «vocês acham que todos têm chances iguais ou diferentes de ser escolhido como primeira } \\
\text { dupla», segunda e assim por diante? «Por que vocês acham isso?». Finaliza a aplicação, sorteando } \\
\text { as duplas com as fichas em EVA numeradas, e discute com eles se essa nova forma é justa, isto é, se } \\
\text { todos têm chances iguais ou diferentes de serem escolhidos como primeiro, segundo, etc. }\end{array}$ \\
\hline 2. ${ }^{a}$ & $\begin{array}{l}\text { Pode ser explorado o conceito de chance com eventos equiprováveis. } 0 \text { professor inicia, explican- } \\
\text { do para quem vai tocar a campainha que deve registrar, na colmeia normal, o movimento do seu } \\
\text { companheiro, utilizando as fichas em EVA, a face F representa andar para Frente e a face D repre- } \\
\text { senta andar para Direita. Começa a brincadeira, sendo que cada dupla faz um primeiro movimento, } \\
\text { depois o segundo movimento até que todos os alunos saiam do tabuleiro. Em seguida, inverte as } \\
\text { ações dos alunos de cada dupla e reinicia a brincadeira. Depois faz os seguintes questionamen- } \\
\text { tos: «Vocês acham que essa forma proposta de movimentação no tabuleiro é justa?» Ou seja, vocês } \\
\text { acham que o aluno tem chances iguais ou diferentes de andar para FRENTE (som pim) ou para DIREITA } \\
\text { (som pom)?» «Por que vocês acham isso?». Finaliza, discutindo coletivamente as respostas. }\end{array}$ \\
\hline 4. & $\begin{array}{l}\text { Pode ser explorado o conceito de chance com eventos não equiprováveis. } 0 \text { professor inicia } \\
\text { fazendo um ou dois experimentos como exemplos e, em seguida, solicita que cada aluno faça mais } \\
\text { dois ou três experimentos, até totalizar 32. Explica que eles devem tocar a campainha, se movi- } \\
\text { mentar sobre o tabuleiro de acordo com o som emitido, bem como registrar no chão o presente } \\
\text { que o amigo recebe pela visita, formando também no chão um pictograma 3D com os resultados da } \\
\text { experimentação. Ao final da experimentação faz os seguintes questionamentos: «Depois do sorteio } \\
\text { vocês acham que todos os amigos têm a mesma chance de ser visitado por Jefferson? Por que vocês } \\
\text { acham isso?». Discute coletivamente os resultados, permitindo que os alunos identifiquem quem } \\
\text { foi o amigo mais visitado, o menos visitado. }\end{array}$ \\
\hline
\end{tabular}




\begin{tabular}{|l|l|} 
5.. & $\begin{array}{l}\text { Pode ser explorado o conceito de chance com eventos equiprováveis. } 0 \text { professor inicia, contando } \\
\text { a história da SE PAJ5. Entrega o tabuleiro em miniatura, pede para colar as casas e faz os seguin- } \\
\text { tes questionamentos: «Sem fazer o sorteio, queremos saber: vocês acham que todos os amigos } \\
\text { têm chances iguais ou diferentes de serem visitados por Jefferson? Por que vocês acham isso?». Em } \\
\text { seguida, entrega as peças em miniatura: colmeia, as fichas em EVA com letras e os presentes em } \\
\text { copos encaixados no porta-copos, e solicita que eles descubram todos os caminhos possíveis para } \\
\text { Jefferson chegar à casa de cada um dos amigos. Após esse passo, questiona: «Vocês acham que } \\
\text { todos os amigos têm chances iguais ou diferentes de serem visitados por Jefferson? Por que vocês } \\
\text { acham isso?». Discute coletivamente os resultados e finaliza a tarefa, solicitando que cada aluno } \\
\text { faça dois ou três experimentos até totalizar } 32 \text { experimentos e questiona: «Depois do sorteio vocês } \\
\text { acham que todos os amigos têm a mesma chance de ser visitado por Jefferson? Por que vocês acham } \\
\text { isso?». Discute coletivamente os resultados, permitindo que os alunos identifiquem quem foi o } \\
\text { amigo mais visitado e o menos visitado. }\end{array}$
\end{tabular}

\section{Quadro 2.}

Descrição de quatro tarefas da SE PAJ.

Fonte: Kataoka, Carvalho y Cazorla (2017).

\section{Metodologia}

Neste artigo, apresentamos uma discussão teórica, focando a análise da MT na perspectiva da DUA, apenas para a terceira tarefa e as peças utilizadas em seu desenvolvimento, a saber: tabuleiro, presentes, casas, fichas e colmeias, todos em miniatura, bem como o porta-copos. Apesar de não apresentarmos nesse artigo resultados de aplicações práticas das nossas pesquisas anteriores com a MT, estes serviram indiretamente como suporte teórico tanto para refletir e compreender as potencialidades dessa tarefa para abordagem do conceito de chance, como para verificar o funcionamento das peças utilizadas dentro de um contexto específico.

Dividimos essa avaliação em duas etapas, a primeira, considerando como categorias de análise os pontos de verificação das três diretrizes do Princípio 1 , buscando assim identificar nessa tarefa e na form a de uso das peças, elementos que pudessem contemplar os indicativos de cada um dos pontos de verificação dessas diretrizes, baseado na descrição deles, apresentados nos Quadros 3, 4 e 5.

Já na segunda etapa, foram utilizadas, como categorias de análise, apenas as diretrizes dos Princípios 2 e 3, já descritos na seção «Desenho Universal para Aprendizagem (DUA)». A opção pela avaliação apenas de uma tarefa e a divisão em duas etapas, uma mais detalhada e outra mais sucinta, advém apenas da limitação do número de páginas para a composição do texto, que nos conduziu a restringir o escopo da análise. No documento do Cast (2011), para cada ponto de verificação das diretrizes do Princípio 1, são apresentados exemplos de como implementá-los, sendo estes tomados também como base para as nossas análises. 


\begin{tabular}{|l|l|l|}
\hline Diretriz & Pontos de verificação & Descrição \\
\hline \multirow{2}{*}{1.1} & $\begin{array}{l}1.1 .1 \text { Oferecer meios de } \\
\text { personalização na apresen- } \\
\text { tação da informação }\end{array}$ & $\begin{array}{l}\text { 0 material deve ser maleável, fornecendo opções para aumentar a } \\
\text { clareza na percepção e o destaque da informação para uma ampla } \\
\text { gama de alunos e permitindo ajustes para preferências de outros }\end{array}$ \\
\cline { 2 - 4 } & $\begin{array}{l}1.1 .2 \text { Oferecer alternativas } \\
\text { à informação auditiva }\end{array}$ & $\begin{array}{l}\text { Para garantir que todos os alunos tenham acesso ao aprendizado, } \\
\text { devem estar disponíveis opções para qualquer informação apresen- } \\
\text { tada auditivamente. }\end{array}$ \\
\cline { 2 - 4 } & $\begin{array}{l}1.1 .3 \text { Oferecer alternativas } \\
\text { à informação visual }\end{array}$ & $\begin{array}{l}\text { Imagens, gráficos, vídeos, animações ou textos podem ser ótimas } \\
\text { formas de apresentar a informação, mas, para garantir que todos } \\
\text { os alunos tenham acesso igual à informação, é essencial fornecer } \\
\text { alternativas não visuais. }\end{array}$ \\
\hline
\end{tabular}

\section{Quadro 3.}

Pontos de verificação da primeira diretriz do Princípio 1. Fonte: elaborado pelos autores com base em informações retiradas do Cast (2011).

\begin{tabular}{|c|c|c|}
\hline Diretriz & Pontos de verificação & Descrição \\
\hline \multirow[t]{5}{*}{1.2} & $\begin{array}{l}\text { 1.2.1 Esclarecer terminologia } \\
\text { e símbolos }\end{array}$ & $\begin{array}{l}\text { Para garantir a acessibilidade de todos, o vocabulário- chave, } \\
\text { rótulos, ícones e símbolos devem estar vinculados ou associados a } \\
\text { representações alternativas de seu significado. }\end{array}$ \\
\hline & $\begin{array}{l}\text { 1.2.2 Esclarecer a sintaxe } \\
\text { e a estrutura }\end{array}$ & $\begin{array}{l}\text { Para garantir que todos os alunos tenham acesso igual à in- } \\
\text { formação, devem-se fornecer representações alternativas que } \\
\text { esclareçam, ou tornem mais explícitas a sintaxe ou as relações } \\
\text { estruturais entre os significados dos elementos. }\end{array}$ \\
\hline & $\begin{array}{l}\text { 1.2.3 Apoiar a descodifi- } \\
\text { cação do texto, notações } \\
\text { matemáticas e símbolos }\end{array}$ & $\begin{array}{l}\text { Para garantir que todos os alunos tenham acesso igual ao conhe- } \\
\text { cimento, pelo menos quando a capacidade de decodificar não for } \\
\text { o foco da instrução, é importante fornecer opções que reduzam } \\
\text { as barreiras que a decodificação gera para alunos que não estão } \\
\text { familiarizados com os símbolos. }\end{array}$ \\
\hline & $\begin{array}{l}\text { 1.2.4 Promover a compreen- } \\
\text { são em diferentes idiomas }\end{array}$ & $\begin{array}{l}\text { Fornecer alternativas, especialmente para vocabulário ou infor- } \\
\text { mações importantes em diferentes idiomas. }\end{array}$ \\
\hline & $\begin{array}{l}\text { 1.2.5 Ilustrar com exemplos, } \\
\text { usando diferentes mídias }\end{array}$ & $\begin{array}{l}\text { Fornecer alternativas -especialmente ilustrações, simulações, } \\
\text { imagens ou gráficos interativos- que possam envolver informação } \\
\text { em texto mais compreensível para qualquer aluno e acessível para } \\
\text { alguns que achariam completamente inacessível o texto. }\end{array}$ \\
\hline
\end{tabular}

\section{Quadro 4.}

Pontos de verificação da segunda diretriz do Princípio 1. Fonte: elaborado pelos autores com base em informações retiradas do Cast (2011). 


\begin{tabular}{|l|l|l|}
\hline Diretriz & Pontos de verificação & Descrição \\
\hline 1.3 & $\begin{array}{l}\text { 1.3.1 Ativar ou fornecer } \\
\text { conhecimento prévio }\end{array}$ & $\begin{array}{l}\text { Apresentar a informação de uma forma mais acessível e susceptível } \\
\text { de ser assimilada pelos alunos, pois isso prepara, ativa ou fornece } \\
\text { qualquer conhecimento prévio. }\end{array}$ \\
\cline { 2 - 4 } & $\begin{array}{l}\text { 1.3.2 Evidenciar padrões, } \\
\text { pontos essenciais, ideias } \\
\text { principais e conexões }\end{array}$ & $\begin{array}{l}\text { Fornecer sugestões explícitas ou comandos que auxiliam os } \\
\text { indivíduos a atender às características mais importantes, evitando } \\
\text { aqueles que importam menos. }\end{array}$ \\
\cline { 2 - 4 } & $\begin{array}{l}\text { mento da informação, a vi- } \\
\text { sualização e a manipulação }\end{array}$ & $\begin{array}{l}\text { Ofertar materiais bem projetados, tendo em vista que proporcionar } \\
\text { modelos personalizados e integrados, apoios e feedback ajuda os } \\
\text { alunos com diferentes habilidades no uso efetivo e eficaz dessas } \\
\text { estratégias. }\end{array}$ \\
\cline { 2 - 4 } & $\begin{array}{l}\text { 1.3.4 Maximizar o transferir } \\
\text { e generalizar }\end{array}$ & $\begin{array}{l}\text { Incluir técnicas que são projetadas para aumentar a memorização, } \\
\text { generalizaçção e conexão da informação, bem como as que indu- } \\
\text { zem e orientam os alunos a empregarem estratégias. }\end{array}$ \\
\hline
\end{tabular}

\section{Análise}

\subsection{Primeira etapa}

Na terceira tarefa (situação dos caminhos possíveis), pode ser explorado o conceito de chance com eventos não equiprováveis. 0 professor inicia, contando de forma teatral no tabuleiro no chão, a história da SE PAJ 3 amigos (Figura 6), acrescentando as casas, e pedindo que um dos alunos, com auxílio dos demais, se movimente no tabuleiro, indicando um caminho para chegar à casa de Babi. Em seguida, distribui, para cada dupla, as miniaturas do tabuleiro e das casas de Jefferson e seus amigos e pede que coloquem as casas na mesma posição do tabuleiro no chão. Faz os seguintes questionamentos: «Sem fazer o sorteio, queremos saber: vocês acham que todos os amigos têm chances iguais ou diferentes de serem visitados por Jefferson? Quadro 5.

Pontos de verificação da terceira diretriz do Princípio 1. Fonte: elaborado pelos autores com base em informações retiradas do Cast (2011).

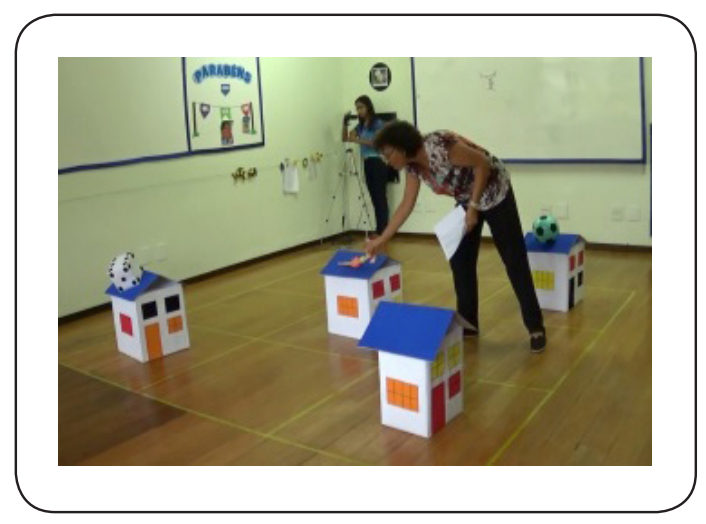

Figura 6.

Exemplos de uma pesquisadora contando a história da SE PAJ 3 amigos. Fonte: Almeida (2017, p. 113).

Por que vocês acham isso?».

Discute coletivamente as respostas, e depois pede aos alunos para explorarem as seguintes peças, em miniaturas: colmeia, fichas em EVA com uma face 
com a letra $\mathrm{F}$ e outra com a letra $\mathrm{D}$ e os presentes no porta-copos, reforçando que comparem com as peças de tamanho normal, utilizadas nas atividades feitas no chão. Cada peça deve ser entregue separadamente, dando um tempo para exploração. Dando continuidade, o professor solicita aos alunos que registrem na colmeia todos os caminhos possíveis para Jefferson chegar à casa de cada um dos amigos, utilizando as fichas, e que coloquem no próximo espaço da mesma linha da colmeia o presente que 0 amigo ganha de Jefferson. 0 s alunos devem encontrar um caminho para chegar à casa de Pelé, sendo o presente o dado, dois para a casa de Babi representadas pelas bonecas e um para a casa de Pelé com a bola (Figura 7).

Aguarda todas as duplas finalizarem, e pede para arrumarem numa colmeia limpa os presentes que Jefferson deu aos seus amigos, formando assim um Pictograma 3D (Figura 8). Depois faz os seguintes

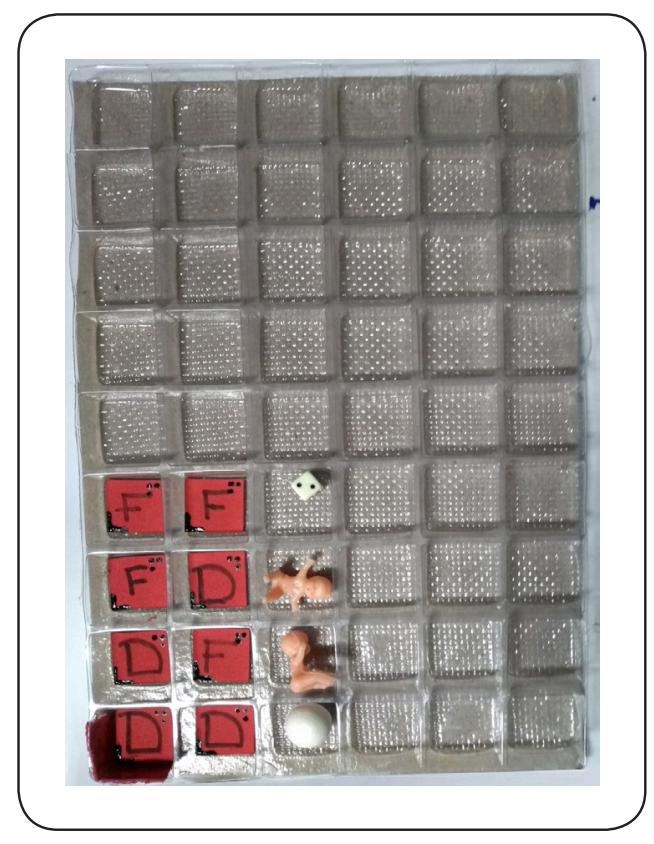

Figura 7.

Exemplo dos registros de caminhos possiveis (com as fichas) e dos presentes na colmeia. Fonte: Kataoka, Carvalho y Cazorla (2017). questionamentos, oralmente ou por escrito, para cada dupla separadamente; (a resposta também pode ser por escrito ou oral): «Agora que vocês acharam todos os caminhos possiveis para Jefferson chegar à casa de cada um dos amigos, queremos saber: vocês acham que todos os amigos têm chances iguais ou diferentes de serem visitados por Jefferson? Por que vocês acham isso?»

Finaliza a tarefa, discutindo coletivamente os resultados para que todos possam compreender, se ainda não tiverem percebido no questionamento anterior, que Babi tem mais chance de ser visitada por Jefferson do que Pelé ou Duda, sendo que esses dois últimos têm a mesma chance.

Como dito, nesta primeira etapa, analisaremos essa tarefa, considerando os pontos de verificação das três diretrizes do princípio 1, descrevendo em que eles são ou não contemplados na tarefa. 0 s resultados para primeira diretriz são mostrados no Quadro 6.

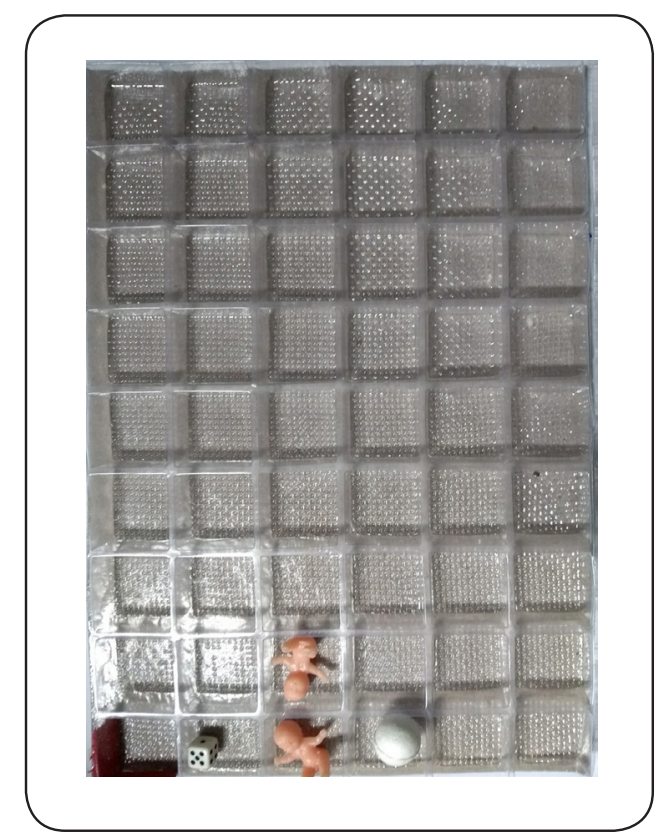

Figura 8.

Exemplo do pictograma 3D na colmeia usando os presentes.

Fonte: Kataoka, Carvalho y Cazorla (2017). 


\begin{tabular}{|c|c|c|}
\hline Diretriz & Pontos de verificação & Análise \\
\hline \multirow[t]{3}{*}{1.1} & $\begin{array}{l}\text { 1.1.1 Oferecer meios de } \\
\text { personalização na apresen- } \\
\text { tação da informação }\end{array}$ & $\begin{array}{l}\text { As peças apresentadas em dois tamanhos, normal e miniatura, } \\
\text { possibilitam a comparação e, se necessário, o uso de apenas } \\
\text { uma das versões. Além disso, no caso do tabuleiro, foram usadas } \\
\text { diferentes cores, texturas e espessuras, favorecendo, por exemplo, } \\
\text { a disposição visual desses elementos. } 0 \text { uso do pictograma 3D, } \\
\text { como recurso gráfico, bem como das colmeias e das fichas para } \\
\text { representar a árvore de possibilidades diferente dos moldes usuais } \\
\text { (Figura 9) pode oportunizar a discussão do conceito de chance. }\end{array}$ \\
\hline & $\begin{array}{l}\text { 1.1.2 Oferecer alternativas } \\
\text { à informação auditiva }\end{array}$ & $\begin{array}{l}\text { A tarefa possibilita a apresentação em Libras (com a presença de } \\
\text { intérprete) ou escrita, pois o formato passo a passo facilita que o } \\
\text { aluno possa ir acompanhando a orientação do professor. }\end{array}$ \\
\hline & $\begin{array}{l}\text { 1.1.3 Oferecer alternativas } \\
\text { à informação visual }\end{array}$ & $\begin{array}{l}\text { Já existe a tarefa na versão escrita em língua materna, em Braille e } \\
\text { com áudio/voz (foram utilizados sintetizadores digitais de texto). } \\
\text { As peças proporcionam opções táteis diferenciadas, por exemplo, } \\
\text { na ficha a escrita em Braille ou em língua materna das letras D } \\
\text { e F, os presentes que são bem diferentes em termos de formato, } \\
\text { tamanho, além disso o EVA colado no canto do tabuleiro e da } \\
\text { colmeia que indica a posição de uso dessas peças (Figura 10). }\end{array}$ \\
\hline
\end{tabular}

Quadro 6.

Análise da terceira tarefa da SE PAJ, de acordo com os pontos de verificação da primeira diretriz. Fonte: Kataoka, Carvalho y Cazorla (2017).

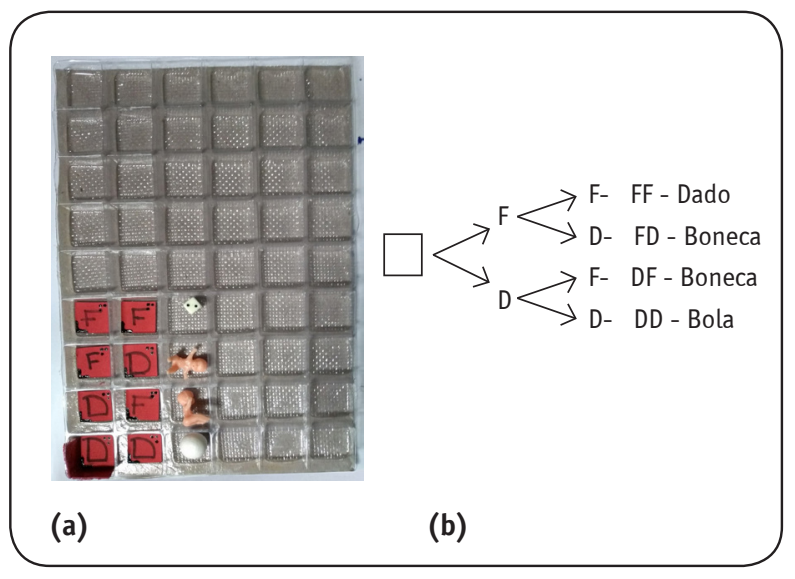

\section{Figura 9.}

Comparação entre a árvore de possibilidade com a colmeia (a) e nos moldes usuais (b) Fonte: Kataoka, Carvalho y Cazorla (2017).

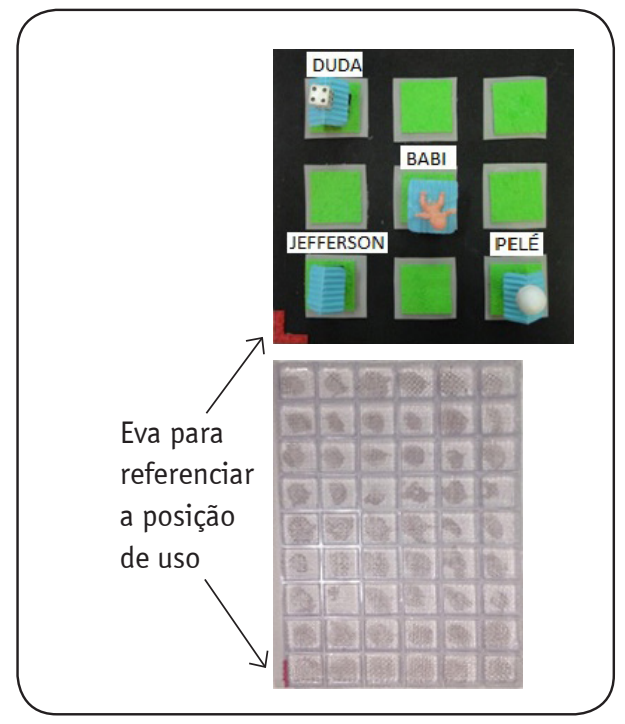

Figura 10.

EVAa para referenciar a posição de uso do tabuleiro e da colmeia (Guia de referência). Fonte: Kataoka, Carvalho y Cazorla (2017). 
Avaliando os resultados apresentados no Quadro 6 , julgamos que essa tarefa, bem como as peças envolvidas, contemplam de forma satisfatória os indicativos da primeira diretriz, o que pode auxiliar na abordagem do conceito de chance, associada à quantidade de caminhos possíveis (por meio das fichas com as letras F e D) ou aos presentes para Jefferson chegar à casa de cada um dos amigos. No Quadro 7 apresentamos a análise, considerando os pontos de verificação da segunda diretriz.

Observando os resultados do Quadro 7, analisamos que, de uma forma geral, esta tarefa, bem como as peças envolvidas, também contemplam os indicativos dessa diretriz. No caso do princípio 1.2.1, a pergunta que se repete em todas as tarefas, sobre as chances iguais ou não, mudando-se apenas o contexto, pode fomentar as associações entre esse conceito e os caminhos, bem como os presentes, portanto, auxiliando na compreensão dele0 ponto 1.2.4, pode ser atendido, desde que haja a necessidade de tradução das tarefas da SE PAJ para diferentes idiomas.

Nos Quadros 8 e 9, apontamos a análise, levando em conta os pontos de verificação da terceira diretriz. Diante dos resultados dos Quadros 8 e 9, refletimos que essa tarefa e as peças utilizadas contemplam também, de forma satisfatória, os pontos de verificação dessa terceira diretriz, possibilitando assim que 0 aluno, por meio de associações e generalizações, possa trabalhar, de forma gradativa, o conceito de chance a cada tarefa.

\begin{tabular}{|c|c|c|}
\hline Diretriz & Pontos de verificação & Análise \\
\hline \multirow[t]{5}{*}{1.2} & $\begin{array}{l}\text { 1.2.1 Esclarecer terminolo- } \\
\text { gia e símbolos }\end{array}$ & $\begin{array}{l}\text { Antes do desenvolvimento dessa terceira tarefa, o aluno tem possibi- } \\
\text { lidade de vivenciar, nas duas tarefas anteriores, situações que podem } \\
\text { favorecer a familiarização com a terminologia e as peças utilizadas. } \\
\text { Destacamos também o uso do termo chance ao invés de probabilidade, } \\
\text { procurando aproximar o aluno de um conceito mais intuitivo, e que, in- } \\
\text { clusive, em tarefas anteriores foi associado também ao conceito de justo. }\end{array}$ \\
\hline & $\begin{array}{l}\text { 1.2.2 Esclarecer a sintaxe } \\
\text { e a estrutura }\end{array}$ & $\begin{array}{l}\text { As conexões que podem ser estabelecidas entre as peças em tamanho } \\
\text { normal e as miniaturas, bem como as conversões da simbologia das } \\
\text { fichas com o caminho, deste com o presente, e por fim com o amigo } \\
\text { visitado de forma mais direta, podem auxiliar no esclarecimento das } \\
\text { funções das peças e na associação com o conceito de chance. Por } \\
\text { exemplo, se caminhar Frente (F), ganha um dado, que representa o } \\
\text { amigo Duda, e logo a chance desse amigo ser visitado por Jefferson } \\
\text { será de } 1 \text { em } 4 \text { caminhos possíveis. }\end{array}$ \\
\hline & $\begin{array}{l}\text { 1.2.3 Apoiar a descodifi- } \\
\text { cação do texto, notações } \\
\text { matemáticas e símbolos }\end{array}$ & $\begin{array}{l}\text { A forma de aplicação da tarefa, passo a passo, pode possibilitar ao } \\
\text { professor ou aos próprios alunos interferirem no processo: explican- } \\
\text { do, auxiliando, correlacionando, reforçando as múltiplas represen- } \\
\text { tações, além do que foi analisado no ponto 1.2.2. }\end{array}$ \\
\hline & $\begin{array}{l}\text { 1.2.4 Promover a compre- } \\
\text { ensão em diversos idiomas }\end{array}$ & Não se aplica. \\
\hline & $\begin{array}{l}\text { 1.2.5 Ilustrar com exemplos, } \\
\text { usando diferentes mídias }\end{array}$ & Contemplado, conforme exemplificado nos pontos 1.2 .1 a 1.2.3. \\
\hline
\end{tabular}

Quadro 7.

Análise da terceira tarefa da SE PAJ, de acordo com os pontos de verificação da segunda diretriz. Fonte: Kataoka, Carvalho y Cazorla (2017). 


\begin{tabular}{|c|c|c|}
\hline Diretriz & Pontos de verificação & Análise \\
\hline \multirow[t]{3}{*}{1.3} & $\begin{array}{l}\text { 1.3.1 Ativar ou fornecer } \\
\text { conhecimento prévio }\end{array}$ & $\begin{array}{l}\text { As tarefas anteriores possibilitam estabelecer ou retomar conheci- } \\
\text { mentos prévios para o desenvolvimento desta tarefa; com o uso de } \\
\text { uma pergunta que se repete, adequando apenas o contexto de cada } \\
\text { situação: «Vocês acham que todos os amigos têm chances iguais ou } \\
\text { diferentes de serem visitados por Jefferson? Por que vocês acham } \\
\text { isso?». Além do uso do contexto de movimentação acontecer num } \\
\text { bairro, numa visita a amigos. }\end{array}$ \\
\hline & $\begin{array}{l}\text { 1.3.2 Evidenciar } \\
\text { padrões, pontos } \\
\text { essenciais, ideias } \\
\text { principais e conexões }\end{array}$ & $\begin{array}{l}\text { São usados esquemas, representações gráficas para evidenciar o } \\
\text { conceito de chance, mas sempre conectando-as com as duas tarefas } \\
\text { anteriores, uma vez que é a expansão da ideia de movimentação } \\
\text { sobre o tabuleiro, do uso das fichas de registro, da relação entre } \\
\text { os amigos e os presentes recebidos. Com foco específico, agora, na } \\
\text { determinação de todos os caminhos possíveis para que Jefferson } \\
\text { possa chegar à casa de cada um dos amigos. E para auxiliar ainda } \\
\text { mais, nessa tarefa, aevidenciação das ideias principais, de padrões e } \\
\text { conexões entre as peças - movimento, caminho-, utiliza-se também, } \\
\text { como exemplo inicial, a determinação de um caminho para Jefferson } \\
\text { chegar à casa de Babi, dando indicativos de como determinar o outro } \\
\text { caminho para a casa dessa amiga e dos outros dois amigos. E partin- } \\
\text { do então, da determinação dos caminhos e da construção do picto- } \\
\text { grama 3D, espera-se que o aluno possa estabelecer uma relação com } \\
\text { o conceito de chance de visita de Jefferson a cada um dos amigos. }\end{array}$ \\
\hline & $\begin{array}{l}\text { 1.3.3 Orientar o } \\
\text { processamento } \\
\text { da informação, a } \\
\text { visualização e a } \\
\text { manipulação }\end{array}$ & $\begin{array}{l}\text { A tarefa é bem descritiva, explicita cada etapa para a aplicação de } \\
\text { forma sequenciada e gradativa. As peças proporcionam aos alunos } \\
\text { diferentes métodos e estratégias de organização. Utiliza-se um con- } \\
\text { texto familiar: amigos, bairros, casas, presentes, movimentação para } \\
\text { frente, direita. A distribuição gradual das peças pode auxiliar também } \\
\text { na eliminação de elementos de distração. }\end{array}$ \\
\hline
\end{tabular}

\section{Quadro 8.}

Análise da terceira tarefa, de acordo com os três primeiros pontos de verificação da terceira diretriz.

Fonte: Kataoka, Carvalho y Cazorla (2017). 


\begin{tabular}{|c|c|c|}
\hline Diretriz & Pontos de verificação & Análise \\
\hline 1.3 & $\begin{array}{l}\text { 1.3.4 Maximizar o } \\
\text { transferir e generalizar }\end{array}$ & $\begin{array}{l}\text { Com o registro dos caminhos possíveis na colmeia é possível recupe- } \\
\text { rar as informações, como, por exemplo, saber que, para se chegar à } \\
\text { casa de Pelé, é preciso caminhar duas quadras para Direita, logo deve } \\
\text { ter duas fichas com a letra D, além do presente, que é uma bola, e } \\
\text { que se encontra também no telhado da sua casa. Assim como o picto- } \\
\text { grama 3D, em que deve ter } 1 \text { bola, } 2 \text { bonecas e } 1 \text { dado. Traz o apoio } \\
\text { para conectar a nova informação com os conhecimentos prévios, e } \\
\text { prepara o aluno para a realização da quinta tarefa, em que se observa } \\
\text { uma possibilidade de generalização dos resultados obtidos nessa } \\
\text { tarefa, uma vez que há um aumento de } 3 \text { para } 5 \text { amigos, de camin- } \\
\text { har de } 2 \text { para } 4 \text { quadras, logo um aumento de } 4 \text { para } 16 \text { caminhos } \\
\text { possíveis, permitindo, por exemplo, que o aluno observe que Babi } \\
\text { que só tinha 2, agora, na quinta tarefa, terá } 4 \text { possibilidades (Figura } \\
\text { 11). Na quinta tarefa, são acrescidos mais dois amigos: Beto, sendo o } \\
\text { presente um botão; e Abel, um anel. Espera-se assim que o exercício } \\
\text { inicial, que envolvia } 3 \text { amigos, posso levar o aluno a estabelecer } \\
\text { relações coerentes com essa nova proposta, abrindo uma possibilida- } \\
\text { de de generalização, , ou seja, o padrão para Jefferson visitar a cada } \\
\text { um dos amigos, para um número maior de amigos, não se restringe } \\
\text { somente para a quinta tarefa, que como dito, já apresenta } 5 \text { amigos. }\end{array}$ \\
\hline
\end{tabular}

Quadro 9.

Análise da terceira tarefa, de acordo com o quarto ponto de verificação da terceira diretriz.

Fonte: Kataoka, Carvalho y Cazorla (2017).

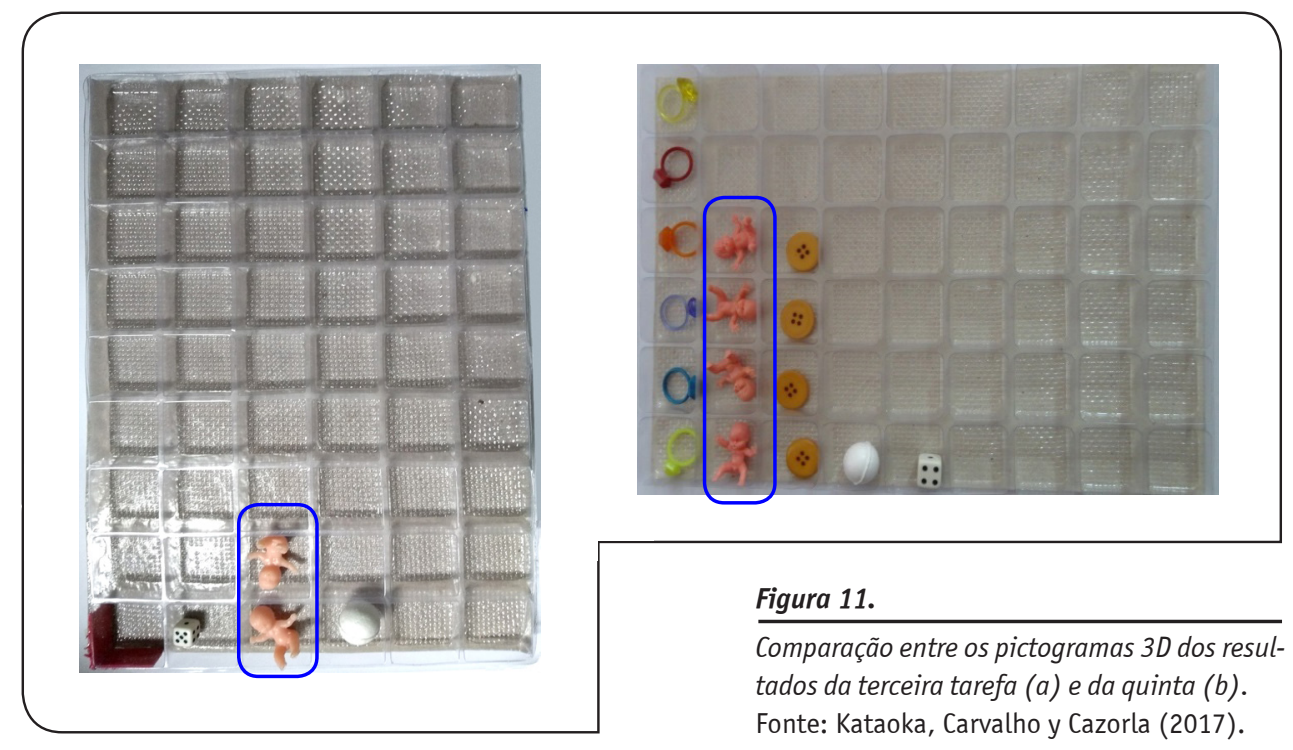




\subsection{Segunda etapa}

Como dito, nesta etapa, avaliamos a terceira tarefa e as peças, utilizando como categorias de análise apenas as diretrizes dos Princípios 2 e 3 da DUA. Mas inicialmente, precisamos pontuar que, de acordo com Cast (2011), entende-se função executiva como

habilidades associadas com a atividade cerebral do córtex pré-frontal, que permitem que os homens superem as reações impulsivas, reações de curto prazo em seu ambiente e, em vez disso, atuem estabelecendo metas ou objetivos de longo prazo, um plano de estratégias eficazes para atingir seus objetivos, monitore seu progresso e modifique os que forem necessários (pp. 25-26).

Ademais, segundo ainda o Cast (2011), ao se buscarem alternativas para proporcionar opções para autorregulação da aprendizagem, deve se estar atento em «fornecer alternativas suficientes para ajudar os alunos com experiências anteriores e di- ferentes habilidades a administrar de forma eficaz a maneira como estes se envolvem em sua própria aprendizagem» (p. 34). Feitas essas duas considerações teóricas, apresentamos a seguir os resultados da análise dessa segunda etapa nos Quadros 10 e 11. Pelos resultados apresentados nos Quadros 9 e 10, acreditamos que essa tarefa e as peças utilizadas contemplam também as diretrizes dos Princípios 2 e 3 da DUA, dando indícios que a forma como a tarefa foi proposta, combinando com o uso das peças, pode auxiliar os alunos na compreensão do conceito de chance. Destaca-se ainda na análise, a importância tanto da possibilidade de interação entre todos os envolvidos no processo, de forma ativa e reflexiva, como das vivências nas tarefas anteriores (processo da ciranda e o movimentação do bairro) para o desenvolvimento dessa tarefa, uma vez que o conceito de chance é explorado em diferentes situações, inclusive sendo solicitado que os alunos sempre justifiquem suas respostas.

\begin{tabular}{|l|l|l|}
\hline Principio & Diretriz & Análise \\
\hline 2 & $\begin{array}{l}\text { 2.1 Proporcionar } \\
\text { opções para a interação } \\
\text { física }\end{array}$ & $\begin{array}{l}\text { Durante toda a execução da tarefa, o aluno tem oportunidade de inte- } \\
\text { ragir com o outro aluno da dupla, com o professor e fisicamente com } \\
\text { as peças da maquete, para perceber o padrão de movimentação no ta- } \\
\text { buleiro, determinar os caminhos possíveis, logo o amigo a ser visitado } \\
\text { e as chances de visita de cada um deles. Ou seja, o aluno deve mani- } \\
\text { pular o tabuleiro em miniatura, identificar o percurso usando os dedos } \\
\text { (tateando), perceber os deslizes e as diferentes texturas dos materiais } \\
\text { utilizados na confeção dessa peça, até mesmo recorrer novamente ao } \\
\text { tabuleiro no chão da sala (utilizados nas duas tarefas anteriores) e se } \\
\text { movimentar sobre ele, usando o seu próprio corpo para determinar os } \\
\text { caminhos possíveis. 0 aluno também manuseará a colmeia, as fichas de } \\
\text { registro, os presentes, buscando por meio da interação física com essas } \\
\text { diferentes peças atingir o objetivo principal da tarefa, qual seja: deter- } \\
\text { minar os caminhos possíveis. Em síntese, o aluno tem a possibilidade } \\
\text { de associar a movimentação no tabuleiro - o registro com as fichas na } \\
\text { colmeia- com o presente, formando o pictograma 3D; de determinar } \\
\text { o número de caminhos de cada amigo e sua relação com as chances de } \\
\text { visita de Jefferson a cada um dos seus amigos. }\end{array}$ \\
\hline
\end{tabular}


2.2 Oferecer opções para expressão e a comunicação

\subsection{Oferecer opções} para as funções executivas
As diferentes formas de registros para transmitir a mesma informação podem auxiliar o aluno no momento de se expressar, de comunicar os resultados, proporcionando, inclusive, a interação entre todos os envolvidos no processo.

Para o desenvolvimento dessa tarefa, o professor tem o papel de conduzir e auxiliar, mas a execução em si exige dos alunos uma atitude proativa, interativa, reflexiva, pautada também nas experiências vivenciadas nas tarefas anteriores. Isso favorece que ele estabeleça suas próprias metas, objetivos e estratégias e até mesmo monitore o seu próprio progresso, já que, no início da tarefa, é questionado se todos os amigos têm a mesma chance de serem visitados por Jefferson. Assim, ele pode, no final, rever se as suas suposições, impressões iniciais se confirmam ou não, avaliando seus conceitos. Tudo isso colabora para que ele aprofunde suas argumentações, suas justificativas.

\section{Quadro 10.}

Análise da terceira tarefa da SE PAJ, de acordo com as diretrizes do princípio 2. Fonte: Kataoka, Carvalho y Cazorla (2017).

\begin{tabular}{|l|l|l|}
\hline Diretriz & Diretriz & Análise \\
\hline 3 & $\begin{array}{l}\text { 3.1 Proporcionar } \\
\text { opções para incentivar } \\
\text { o interesse }\end{array}$ & $\begin{array}{l}\text { A utilização e a manipulação das peças, após o processo da ciranda e } \\
\text { da movimentação do bairro nas tarefas anteriores, podem despertar o } \\
\text { interesse dos alunos na descoberta dos caminhos possíveis, permitir- } \\
\text { lhes mais autonomia no desenvolvimento dessa tarefa. }\end{array}$ \\
\cline { 2 - 4 } & $\begin{array}{l}\text { 3.2 Oferecer opções } \\
\text { para manter o esforço }\end{array}$ & $\begin{array}{l}\text { Perguntas e estímulos constantes do professor e a interação com o ou- } \\
\text { tro aluno da dupla podem auxiliar na manutenção do esforço e da per- } \\
\text { sistência do aluno no desenvolvimento da tarefa, fomentando também } \\
\text { a colaboração e a apropriação cada vez mais do conceito de chance. }\end{array}$ \\
\cline { 2 - 4 } & $\begin{array}{l}\text { 3.3 Oferecer opções } \\
\text { para autorregulação }\end{array}$ & $\begin{array}{l}\text { Essa terceira tarefa possibilita ao aluno ser um ator e não apenas mero } \\
\text { espectador no processo, empreendendo assim esforços próprios, que } \\
\text { podem favorecer a autorregulação da sua aprendizagem durante todas } \\
\text { as ações realizadas. Além disso, o uso de diferentes tipos de registros } \\
\text { e peças, como já descritos nas diretrizes anteriores, pode auxiliar ao } \\
\text { aluno a revisitar, reavaliar seus resultados, confrontar com as expe- } \\
\text { riências vivenciadas nas tarefas anteriores. Inclusive pode dar um } \\
\text { tempo necessário para ele amadurecer suas ideias, já que as discussões } \\
\text { coletivas são recomendadas para ocorrer somente após a conclusão das } \\
\text { tarefas por todas as duplas. }\end{array}$ \\
\hline
\end{tabular}

\section{Quadro 11.}

Análise da terceira tarefa da SE PAJ, de acordo com as diretrizes do princípio 3. Fonte: Kataoka, Carvalho y Cazorla (2017). 


\section{Considerações finais e perspectivas futuras}

Cremos que os resultados apresentados parecem indicar que a MT, mais especificamente a terceira tarefa e as peças utilizadas para seu desenvolvimento, atendem de forma satisfatória aos princípios e às diretrizes do DUA. E a partir desses resultados, é razoável supor que as demais tarefas e peças da MT também possam comtemplar o proposto pelo DUA. Nessa direção, salientamos que, em breve, publicaremos outros artigos que possam comprovar ou não essa suposição.

Refletimos ainda que a análise da MT na perspectiva do DUA, isto é, com esse enfoque didático, nos possibilitou investigar melhor, no ambiente escolar, as características, as potencialidades e a flexibilidade desse material, quando na abordagem do conceito de chance, tendo em vista atender à diversidade dos alunos
Para mais esperamos que esse estudo contribua com as pesquisas envolvendo o DUA, na direção da avaliação e da proposição de materiais didáticos que possam atender a um currículo mais flexibilizado e que, por conseguinte, cheguem até os envolvidos no processo de ensino e aprendizagem, cooperando com uma inclusão, como dito, mais integradora, que contemple a pluralidade dos alunos. Em particular, almejamos também que a MT possa ser utilizada, de fato, no ambiente escolar, auxiliando positivamente no desenvolvimento do letramento probabilístico dos alunos, mediante uma abordagem lúdica, reflexiva de conceitos probabilísticos, mais especificamente, de forma direta, o conceito de chance.

\section{Notas}

(1) Eventos simples e compostos, probabilidade de eventos simples e compostos, situação determinística, experimento aleatório, frequências esperadas e observadas, padrões observados e esperados. (2) Existe também a história da SE PAJ versão 5 amigos, surgindo mais dois novos amigos para Jefferson visitar: Abel e Beto, que colecionam, respectivamente, anel e botão. 0 tabuleiro no chão tem a dimensão ampliada para 5x5m, com 25 quadras, e o tabuleiro miniatura é confeccionado no verso do tabuleiro 3 amigos.

\section{Referências}

Almeida, I.S. da (2017). Esquemas utilizados por estudantes da educação infantil ao resolverem situações envolvendo chance no contexto da maquete tátil. Dissertação (Mestrado em Educação Matemática). Universidade Estadual de Santa Cruz, Ilhéus-Bahia.

Brasil (1997). Parâmetro Curricular Nacional: Matemática, $1^{\circ}$ e $2^{\circ}$ ciclos do Ensino Fundamental 1. Brasília: Ministério da Educação /Secretaria de Educação Fundamental.

Brasil (1988a). Referencial curricular nacional para a educação infantil. Vols. 1, 2 e 3, Brasília: Ministério da Educação /Secretaria de Educação Fundamental.

Brasil (1998b). Parâmetros Curriculares Nacionais: adaptações curriculares. Brasília: Ministério da Educação/Secretaria de Educação Especial.

Brasil (2005). Projeto Escola Viva: garantindo o acesso e permanência de todos os alunos na escola. Brasília: Ministério da Educação /Secretaria de Educação Especial.

Brasil (2006). Orientações Curriculares Nacionais para o Ensino Médio. 2. Brasília: Ministério da Educação /Secretaria de Educação Básica. 
Brasil (2010). Marcos Político-Legais da Educação Especial na Perspectiva da Educação Inclusiva. Brasília, Secretaria de Educação Especial.

Brasil (2018). Base Nacional Comum Curricular (BNCC). Brasília, MEC/CONSED/UNDIME. Recuperado em (10 jan 2020), de http://basenacionalcomum.mec.gov.br/images/BNCC_EI_EF_110518_versaofinal_site.pdf Calegari, E.P., Da Silva, R.S. \& Da Silva, R.P. (2014). Design Instrucional e Design Universal para a Aprendizagem: Uma Relação que Visa obter Melhorias na Aprendizagem. Revista D.: Design, Educação, Sociedade e Sustentabilidade, 1(5), 29-48. Recuperado em (15 dez 2019), de http://seer.uniritter. edu.br/index.php/revistadesign/article/view/724/486.

Cast (2011). Universal Design for learning guidelines version 2.0 [graphic organizer]. Wakefield, MA: Author. Recuperado em (10 set 2019), de http://udlguidelines.cast.org/binaries/content/assets/ udlguidelines/udlg-v2-0/udlg_graphicorganizer_v2-0.pdf.

Cazorla, I.M. (2006). Teaching statistics in Brazil. Proceedings of the $7^{\text {th }}$ International Conference on teaching Statistics, Salvador: Brasil, $7^{\text {th }}$. Recuperado em (10 set 2019), de https://www.ime.usp. br/ abe/ICOTS7/Proceedings/index.html.

Chtena, N. (2016). Teaching tips for an UDL-Friendly Classroom: Advice for implementing strategies based on Universal Design for Learning. Recuperado em (10 ago 2020), de : https://www.insidehighered.com/ Courey, S. et al. (2012). Improved lesson planning with universal design for learning (UDL). Teacher Education and Special Education, 36, 7-27.

Gal, I. (2005). Towards «probability literacy» for all citizens. In: G.A. Jones (ed.), Exploring probability in school: Challenges for teaching and learning (pp.39-63). USA: Springer.

Movimento Down (2015). Desenho universal para livros didáticos. Recuperado em (10 ago 2020), de: http://www.movimentodown.org.br/wpcontent/uploads/2015/08/Manual-FINAL-bibliografia.pdf Nunes, L., \& Nunes Sobrinho, F. (2008). Acessibilidade. In: C. Baptista, K. Caiado, K., \& D. Jesus (Org.), Educação especial: diálogo e pluralidade (pp. 269-279). Porto Alegre, Brasil: Mediação.

Pastor, C.A., Serrano, J.M.S., \& Del Río, A.Z. (2014). Diseño Universal para el Aprendizaje (DUA) Pautas para su introducción en el currículo. Recuperado em (10 ago 2020), de https://www.educadua. es/doc/dua/dua_pautas_intro_cv.pdf

Rabardel, P. (1995). Les Hommes et les tecnologies: approche cognitive des instruments contemporains. Paris, França: Armand Colin.

Santana, E.R.S. (2010). Estruturas aditivas: o suporte didático influencia a aprendizagem do estudante? Tese de Doutorado em Educação Matemática, Pontifícia Universidade Católica de São Paulo, São Paulo. Vergnaud, G.A. (1983). Multiplicative structures. In: R.A. Lesh \& M. Landau (Eds.), Acquisitions of mathematics concepts and procedures (pp.127-174). New York, USA: Academic Press.

Vita, A.C. (2012). Análise instrumental de uma maquete tátil para a aprendizagem de probabilidade por alunos cegos. Tese de Doutorado em Educação Matemática, Pontifícia Universidade Católica de São Paulo, São Paulo.

Vita, A.C. et al. (2016). Aplicação de tarefas de Probabilidade no contexto da maquete tátil a alunos da educação básica: investigações à luz de teorias da educação matemática (Projeto de pesquisa). Universidade Estadual Santa Cruz, Ilhéus, Bahia, Brasil.

Walichinski, D. \& Santos Junior, G. (2013). Educação Estatística: objetivos, perspectivas e dificuldades. Imagens da Educação, 3(3), 31-37.

Watson, J. (2006). Statistical Literacy at School: Growth and goals. London, UK: Routledge. 


\section{Legislação}

Decreto 6.571, de 17 de setembro de 2008 (2008). Dispõe sobre o atendimento educacional especializado. Presidência da República, Casa Civil, Subchefia para Assuntos Jurídicos, Brasília, DF. Decreto 7.611, de 17 de novembro de 2011 (2011). Dispõe sobre a educação especial, o atendimento educacional especializado e outras providências. Presidência da República, Casa Civil, Subchefia para Assuntos Jurídicos, Brasília, DF.

Lei n. 13.146 de julho de 2015 (2015). Brasília: Presidência da República/Casa Civil. Recuperado em (10 ago 2020) de http://www.punf.uff.br/inclusao/images/leis/lei_13146.pdf

Resolução CNE/CEB n.4/2009 (2009) que estabelece as Diretrizes Operacionais para o Atendimento Educacional Especializado na Educação Básica. Diário Oficial da União. Brasília, Conselho Nacional de Educação. Câmara de Educação Básica, 3 p. 